\title{
Farmers' Demand Desire for Farmland Water Conservancy Facilities in the Perspective of Income ${ }^{\mathbb{1}}$
}

\author{
Wang Lei ${ }^{1}$, Zhao Cunxue ${ }^{1}$,Du Dong ${ }^{1}$ \\ School of Business Administration, Hohai University \\ School of Business Administration, Hohai University, Changzhou City, Jiangsu Province
}

E-mail: 20141924@hhu.edu.cn

\begin{abstract}
Based on the field survey data, hierarchical model was used to analyze willingness and influencing factors of demand for farmland water conservancy facilities of farmers with income difference. The study shows that village characteristics, irrigation expectation deterioration and institutional environment are the main factors influencing farmers' demand. Seen from the results of the income grouping, geographical features, water fee collection rate, deterioration in expected waiting time for irrigation, deterioration in expected irrigation water price are common factors affecting farmers' demand desire for farmland water conservancy facilities, while influence of other factors differs. Farmers' characteristics and planting willingness have no effect on farmers' demand desire. With the increase of income, influencing factors of farmers' demand at the village level are gradually reduced, while those at household level are increased. Policy recommendations are presented based on the findings.
\end{abstract}

Key words: income perspective, farmland water conservancy facilities, demand desire, stratification model

\section{Introduction}

Farmland water conservancy facilities, as one of the most basic rural productive public goods, play an extremely important role in agricultural production (World Bank, 1994; Brown, 1998). With the gradual advancement and deepening of agriculture and rural reform, agricultural production structure, planting structure adjustment and diversification of planting methods, farmers as the ultimate users of farmland water conservancy facilities put forward higher requirements on supply method of farmland water conservancy facilities, with individual demand preferences increasingly prominent.

Farmers in low-income areas have a stronger demand for productive public goods than those in higher-income areas (Chu Yongsheng, 2004). However, in the supply of public goods, high-income earners are the main beneficiaries, while low-income earners benefit few from it (Stigler, 1970). Ciriacy Wantrup (1947) proposed or-estimate method (CV method) to expose preference problems. Subsequently, Kong Xiangzhi and Tu Shengwei (2006) used this theory to study the influencing factors of farmers' demand preference for farmland water conservancy facilities. For the issue of inconsistency in farmers' demand preference, March (1994) considered that it can be resolved through coalition or a team approach based on multiple actors' decision-making theory. Ostrom (1992) studied collective action of supply and maintenance of farmland water conservancy facilities from public choice theory. Zhang Ning et al. (2012) are very concerned about farmers' participation as she believes that improving farmers' participation in management will help improve farmland water conservancy facilities management efficiency and water use efficiency. Zhao Nong, Liu Xiaolu (2008) argued that location factors have an impact on supply of local public goods and that local governments will provide public goods in accordance with the wishes of intermediate voters.

\footnotetext{
(1) This paper is funded by the National Natural Science Foundation of China under the "Research on Participatory Supply of Small - scale
} Farmland Water Conservancy by Farmers under Social Network" (41501126). 
Domestic and foreign scholars have made theoretical and practical discussions on farmland water conservancy facilities supply, demand from different angles, their theory and methods mean important significance in inspiration and reference for this study. However, the scholars' research on farmland water conservancy facilities mainly focuses on farmers' participation and construction, and few people have made deep analysis from the perspective of farmers' demand. Therefore, this paper classifies farmers according to income, and explores the influencing factors that affect farmers' demand desire for farmland water conservancy facilities from the two levels of village and farmer.

\section{Data source, sample description and variable selection}

\subsection{Data source}

Data in this paper is based on the survey of supply situation of farmland water conservancy facilities in rural areas in China from July to August in 2012. In the questionnaire of 750 households, 695 samples were eventually used.

\subsection{Sample description}

The geographical features of the villages are mostly plain which accounts for $63.3 \%$ of the total sample, followed by hills. Most of the villages surveyed are in grain-producing areas, mainly ordinary villages.

From the gender point of view, subjects are mostly male. Seen from level of education, the overall level of education of farmers is relatively low. According to the actual situation of the survey, the total annual agriculture income is divided into three grades, namely, low agricultural income households with5,000 yuan and below, medium agricultural income households with $5001 \sim 20000$ yuan and high agricultural income households with more than 20,000 yuan. According to this classification standard, total annual agriculture income is mainly in the two intervals of $5001 \sim 20000$ yuan $(72.5 \%)$, indicating that total annual agriculture income of farmers is at a moderate level.

\subsection{Farmers' demand desire for farmland water conservancy facilities}

According to the survey, $16.7 \%$ of the farmers had a strong demand for farmland water conservancy facilities; $33.6 \%$ of households indicated demand as the existing farmland water conservancy facilities could not meet the irrigation requirements completely; $14.8 \%$ of the farmers thought it did not matter as the existing facilities basically met the demand; $34.8 \%$ of farmers believed that no new farmland water conservancy facilities were needed. It can be seen that supply of farmland water conservancy facilities cannot meet the needs of most farmers (50.3\%). In general, farmers' demand for farmland water conservancy facilities tends to increase with the increase of agricultural income.

\subsection{Variable selection}

In the study, five independent variables were selected from village layer (geographical features, number of water management staff, total channel length, water fee collection rate and total number of pumping wells), and 10 independent variables of five categories were selected from farmer layer, that is, farmers' characteristics (whether one is head of a household, age, whether one is village cadre), household characteristics (irrigable area ratio, whether there is significant loss in the past three years), irrigation expectation deterioration(deterioration in expected waiting time for irrigation, deterioration in expected irrigation water price), institutional environment (government attention degree, food subsidy incentives), planting willingness (whether one is willing to grow economic crops), while farmers' evaluation of demand desire for farmland water conservancy facilities is selected as dependent variable. 


\section{Empirical analysis}

\subsection{One-way analysis of variance of random effects}

For the results of one-way analysis of variance of random effects, intercept is 3.38, which indicates that degree of farmers' demand for water conservancy facilities was 3.38. The interclass correlation coefficient $\rho$ of farmers' demand desire for farmland water conservancy facilities is significant 0.33 , which suggests that there is a difference in supply of farmland water conservancy facilities between villages. For differences in farmers' demand desire for farmland water conservancy facilities, 33\% differences are due to differences in supply of farmland water conservancy facilities between villages, and $67 \%$ is due to farmers themselves, so stratification model is applicable.

\subsection{Estimation result of random intercept model}

\section{(1) Village characteristics}

Except that geographical characteristics have no effect on high agricultural income farmers, it has a significant impact on farmers of other income groups. In practice, some farmers in high agricultural income groups often have more complete irrigation facilities, such as wells, pumps, water pipes, etc., so that limitation in original geographical conditions is broken through.

The number of water management staff has a significant impact on farmers' demand desire, as the more staff there are, the stronger farmers' demand desire for farmland water conservancy facilities is. More grass-roots farmland water management staff is more likely to cause unclear division of labor, unclear responsibility, overlapping leadership, no responsible person, eventually leading to confused management of farmland water conservancy facilities.

The total channel length has an impact on demand desire of farmers in medium agricultural income group, as the longer the total channel length is, the weaker the farmers' demand desire for farmland water conservancy facilities is. Channel length determines irrigation possibility to some extent. Most of the farmers in medium agricultural income group adopts canal irrigation and has a strong dependence on channel.

Water fee collection rate has a significant impact on farmers' needs, as water fee collection rate can represent management level and marketization of farmland water conservancy facilities. The higher the water fee collection rate is, the higher the supply level of farmland water conservancy facilities is, and the better it can meet farmers' needs.

The total number of pumping wells has a significant impact on farmers' needs, as the more the total number of pumping wells is, the stronger the farmers' demand is. The greater total number of pumping wells indicates that irrigation water source of the area is mainly groundwater. Lack of other water sources drives the demand for groundwater, and correspondingly, demand for pumping wells.

\section{(2) Farmer characteristics}

In the case of farmer characteristics, only the variable of whether one is village cadre has a significant effect on farmers in low agricultural income groups. (3) Household characteristics

Irrigable area ratio has a significant impact on farmers' needs. A higher the irrigable area ratio indicates that supply of farmland water conservancy facilities better meets farmers' needs, thus reducing the farmers' demand for new farmland water conservancy facilities. Household vulnerability affects farmers in low agricultural income groups.

\section{(4) Irrigation expectation deterioration}

Deterioration of expected waiting time for irrigation has a significant impact on farmers' demand desire, as and the longer the waiting time for irrigation is, the stronger the farmers' demand desire will be. Farmers in low agricultural income groups often have less farmland, but their waiting expectation cannot 
change the existing pattern of irrigation, so the farmers downplay their own say in irrigation.

Deterioration in expected irrigation water price has a significant impact on farmers in low and medium agricultural income groups. Farmers hope that increase in the number of farmland water conservancy facilities will ease the high water pressure caused by irrigation stress.

\section{(5) Institutional environment}

The government's emphases on construction of farmland water conservancy facilities and grain subsidy policy incentives have a significant effect on medium and high agricultural income groups. As a result, the group has no excessive demand for farmland water conservancy facilities. Grain subsidy incentives have two opposite effects on medium and high agricultural income groups, with negative effect on medium agricultural income group and positive effect on high agricultural income group.

\section{(6) Planting willingness}

Planting willingness has no significant impact on farmers' demand desire. Despite farmers' decreased enthusiasm in growing food crops after reform and opening up, path dependence on links such as environment, planting, sales, etc. makes farmers more comfortable in the current planting model, resulting in path dependence on farmland irrigation.

Table 1 Estimated results of random intercept model

\begin{tabular}{|c|c|c|c|c|c|c|c|c|}
\hline \multirow{2}{*}{$\begin{array}{l}\text { Variabl } \\
\text { e }\end{array}$} & \multicolumn{2}{|c|}{ overall } & \multicolumn{2}{|c|}{$\begin{array}{l}\text { low agricultural } \\
\text { income group }\end{array}$} & \multicolumn{2}{|c|}{$\begin{array}{l}\text { medium agricultural } \\
\text { income group }\end{array}$} & \multicolumn{2}{|c|}{$\begin{array}{l}\text { high agricultural } \\
\text { income group }\end{array}$} \\
\hline & $\begin{array}{c}\text { Coefficien } \\
\mathrm{t}\end{array}$ & $P$ value & Coefficient & $\begin{array}{c}\mathrm{P} \\
\text { value }\end{array}$ & $\begin{array}{l}\text { Coefficien } \\
\mathrm{t}\end{array}$ & $\mathrm{P}$ value & $\begin{array}{c}\text { Coefficien } \\
\mathrm{t}\end{array}$ & $P$ value \\
\hline $\mathrm{X} 1$ & 1.632 & 0.057 & 1.746 & 0.445 & 7.312 & 0.005 & 0.274 & 0.854 \\
\hline X11 & -0.464 & 0.000 & -0.354 & 0.014 & -0.458 & 0.009 & 0.176 & 0.275 \\
\hline $\mathrm{X} 12$ & -0.034 & 0.001 & -0.486 & 0.436 & -0.175 & 0.057 & -0.541 & 0.017 \\
\hline X13 & 0.022 & 0.065 & 0.014 & 0.982 & 0.047 & 0.340 & 0.035 & 0.470 \\
\hline X14 & 0.856 & 0.002 & 1.045 & 0.024 & 0.512 & 0.012 & 0.401 & 0.494 \\
\hline $\mathrm{X} 15$ & -0.019 & 0.019 & -0.081 & 0.010 & 0.018 & 0.121 & -0.321 & 0.024 \\
\hline \multicolumn{9}{|l|}{$\mathrm{X} 2$} \\
\hline X21 & -0.030 & 0.789 & -0.282 & 0.213 & -0.378 & 0.110 & -0.060 & 0.887 \\
\hline $\mathrm{X} 22$ & -0.059 & 0.341 & 0.117 & 0.192 & -0.184 & 0.193 & -0.247 & 0.321 \\
\hline X23 & 1.027 & 0.001 & 1.90 & 0.014 & 0.378 & 0.124 & 1.824 & 0.116 \\
\hline \multicolumn{9}{|l|}{$\mathbf{X} 3$} \\
\hline X31 & 0.568 & 0.173 & -0.422 & 0.469 & 0.540 & 0.079 & 2.126 & 0.031 \\
\hline X32 & -0.210 & 0.064 & -0.347 & 0.051 & 0.023 & 0.721 & -0.247 & 0.241 \\
\hline \multicolumn{9}{|l|}{ X4 } \\
\hline X41 & -0.041 & 0.000 & -0.004 & 0.286 & -0.127 & 0.007 & -0.045 & 0.090 \\
\hline $\mathrm{X} 42$ & -0.003 & 0.041 & -0.057 & 0.047 & -0.071 & 0.017 & -0.045 & 0.481 \\
\hline \multicolumn{9}{|l|}{ X5 } \\
\hline X51 & 0.131 & 0.068 & -0.163 & 0.452 & 0.153 & 0.031 & -0.057 & 0.021 \\
\hline X52 & -0.230 & 0.048 & 0.245 & 0.250 & -0.281 & 0.097 & 0.150 & 0.066 \\
\hline X6 & -0.131 & 0.357 & -0.358 & 0.232 & -0.512 & 0.164 & -0.763 & 0.132 \\
\hline X61 & 0.212 & 0.035 & 0.457 & 0.052 & 0.224 & 0.014 & 0.433 & 0.058 \\
\hline X62 & 1.224 & & 1.145 & & 1.274 & & 1.325 & \\
\hline
\end{tabular}

X1: intercept

X11: Geographical features; X12: number of water management staff; X13: total channel length; 
X14: water fee collection rate; X15: total number of pumping wells

X2: farmers' characteristics

$\mathrm{X} 21$ : whether one is head of a household; X22: age; X23: whether one is village cadre

\section{X3: household characteristics}

X3: lirrigable area ratio; X32: household vulnerability

X4: irrigation expectation

X41: deterioration in expected waiting time for irrigation; X42: deterioration in expected irrigation water price

\section{X5: institutional environment}

X51: government attention degree; X52: food subsidy incentives

X6: planting willingness

X61: inter-village variation; X62: intra-village variation

\section{Conclusions and recommendations}

The conclusions of this paper are as follows:

First, the main influencing factors that affect farmers' demand desire for farmland water conservancy facilities include village characteristics, irrigation expectation and institutional environment.

Second, seen from the results of agricultural income grouping, geographical features, water fee collection rate, deterioration in expected waiting time for irrigation, deterioration in expected irrigation water price are common factors affecting farmers' demand desire for farmland water conservancy facilities, while influence of other factors differs. Third, with the increase of agricultural income, influencing factors of farmers' demand at the village level are gradually reduced, while those at household level are increased.

Based on the above analysis, the following policy suggestions are put forward: increase cross-region construction of farmland water conservancy facilities, to break through the limitation of geographical features on farmland irrigation; reduce the number of management staff of farmland water conservancy facilities, superior government should supervise the management of farmland water conservancy facilities to improve work efficiency of grass-roots management staff; according to the local situation, appropriately increase construction of small farmland water conservancy facilities like canals, pumping wells to meet the needs of different farmers; shorten regional irrigation cycle, construct emergency irrigation facilities, to ease the pressure of insufficient farmland water conservancy facilities caused by irrigation peak; establish a reasonable water pricing mechanism.

\section{References}

[1]Ostrom, E.: Crafting Institutions for Self-Governing Irrigation Systems, San Francisco: Institute for Contemporary Studies Press, 2(5):493-535, 1992.

[2]James March, C. Heath.: A Primer on Decision Making: How Decision Happen, New York: Free Press, 1994.

[3]George J. Stigler.: Directors' law of Public Income Redistribution, Journal of Law and Economics, 13(1):1-10,1970.

[4]Ciriacy-Wantrup SV.: Capital returns from soil conservation practices, Journal of Farm Economics, 29(4):1181-1196, 1947.

[5]ChuYongSheng, Ding Zixin: The Rural Public Goods Supply and the Consumption Level Correlation Analysis, Problem of Agricultural Economy, 2004, 7: 63-66 
[6]Zhao Nong, Liu Xiaolu: The Location Factors and the Optimal Supply of Public Goods , Economic Research Journal,2008,10:93-103.

[7]Xiang-zhi kong, TuShengWei: In the Construction of New Rural Farmers Demand for Public Goods Preferences and Influencing Factors of Research - in Irrigation and Water Conservancy Facilities, for example, Issues in Agricultural Economy, 2006, 10:10-16

[8]Zhang ning, wen-cong lu, Dong Hongji: The China Water Conservancy Management Efficiency and

Farmer Participatory Mechanism Research, Based on an Empirical Analysis of the Stochastic Frontier, Journal of Natural Resources, 2012, 27 (3):353-363 